\title{
CREATING MOODBOARDS WITH DIGITAL TOOLS: A NEW EDUCATIONAL APPROACH
}

\author{
Fausto Brevi, Manuela Celi, \& Flora Gaetani \\ Department of Design, Politecnico di Milano (Italy)
}

\begin{abstract}
The paper presents methodologies and first results of an educational experimentation (Brevi, Celi, \& Gaetani, 2018) held at the Bachelor of Science in Product Design programme of Politecnico di Milano. In order to build a body of knowledge for Design freshmen, the experience had the aim of matching basic skills developed at the first year with the need of an autonomous approach required at the second year from Metadesign Studio throughout the tools for creating moodboards: a collection of images, colors and texture with the aim of representing emotions, feelings or 'moods', suggested by the design research. Moodboards have an important function in developing students' ability to articulate their thinking.

The enacted experimentation had the aim to present and test some practical tool for moodboards development. During the Methods and Instruments for Design course these skills have been developed through targeted exercises of awareness and techniques of photographic processing. To enable students to act in a more conscious way the educational approach has provided lessons with practical visual examples, a selection of on-line materials and step by step guide with suggestions.
\end{abstract}

Keywords: Metadesign, moodboard, digital tools, integration, photo editing.

\section{Introduction}

In order to manage a good design process, nowadays there is a strong need of quality both on theoretical knowledge and on technical skills. Design is the discipline of practicing through a reflective approach. Many of the courses offered at the first year at the design schools have the aim of building a common ground from both, theoretical (history, maths, materials) and practical perspective (draw, models, photography). When arriving at the second year often students have problems in facing design studios because these tools and the vocabulary that they have acquired are not jet a "design literacy". The Metadesign approach, typical of Industrial Design courses at the Politecnico di Milano, can enhance the ability to tackle problems. In other words through Metadesign students may experience the whole design process, reflecting on it, organizing activities and explicating every cognitive step, finding, developing and internalizing their own design method.

The paper presents methodologies and first results of an educational experimentation held at the Undergraduate Product Design programme of Politecnico di Milano. In order to build a body of knowledge for Design freshmen, the experience had the aim of matching basic skills developed at the first year with the need of an autonomous approach required at the second year from Metadesign Studio especially in communicating pre-project phases and final story-telling. One of the main tools for Metadesign research are the moodboards: a collection of images, colors and texture with the aim of representing emotions, feelings or 'moods', suggested by the design research. Moodboards have an important function in developing students' ability to articulate their thinking. Depending on the field and the state of project development, moodboards can provide a visual description of the overall state of the scenario, communicating its flavours and features in different ways. This visualization phase embody a key step toward a successful concept. The enacted experimentation had the aim to present and test some practical tool for moodboards development. Moodboards' creation requires aesthetic skills and sensibility that can be developed and trained since the early years of the Bachelor of Science in Industrial Design. During the course of Methods and Instruments for Design these skills are developed through targeted exercises of awareness and techniques of photographic processing. To enable students to act in a more conscious way the educational approach has provided lessons with practical visual examples, a selection of on-line materials and step by step guide with suggestions. 


\subsection{The Metadesign educational path in BSc in Product Design at Politecnico di Milano}

At Polimi Design School the study plan is the clear expression of an "inductive approach" to teaching. The Product Design undergraduate program provide specific teaching in design, technological process and communications for industrial products. The courses are characterized by the mutual presence of theory and practice often integrated inside specific learning unit labeled design studio. In this way the project became the device to explore and learn theoretical issues, methods and tools in the mood of Schon's reflective practice (Schön, 1983).

\section{Figure 1. BSc in Product Design educational structure (on the left) and programme (on the right) at Polimi.}

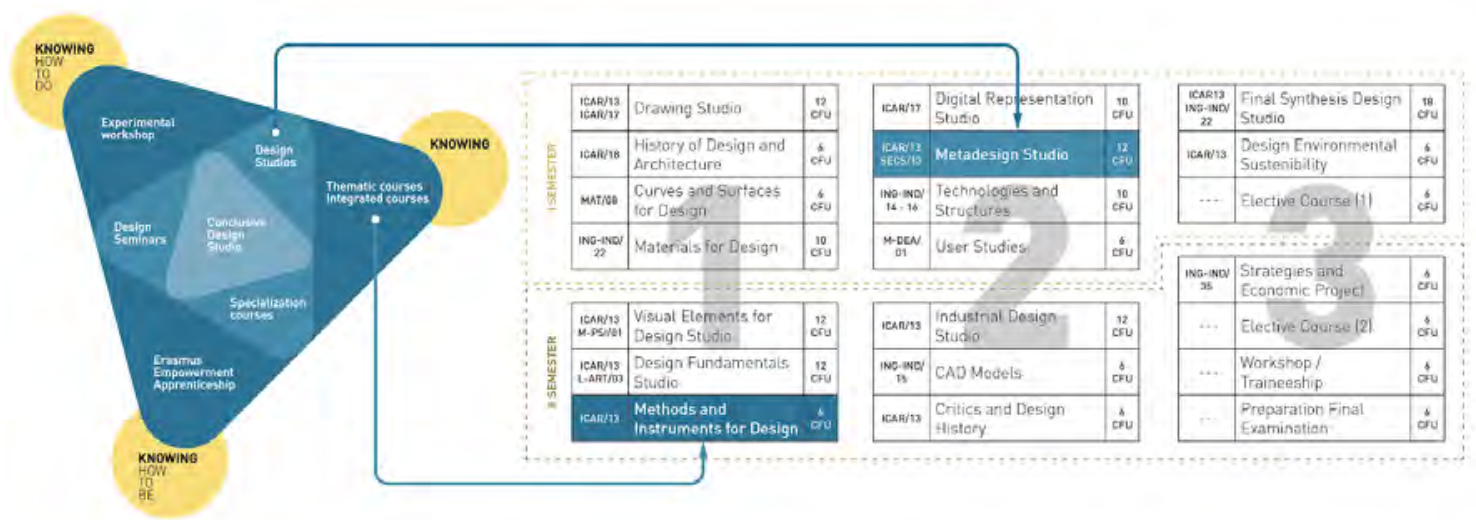

During the educational curriculum of BSc in Product Design, the course Methods and Instruments for Design is inserted in the second semester of the first year and the Metadesign Studio in the first semester of the second year. The course Methods and Instruments for Design is in continuity with the Drawing Studio and it provides educational content organized into two paths: an analog one, dedicated to sketching and freehand rendering and a digital one, aimed at visual communication for project representation of industrial product. The two paths takes place in parallel throughout the course in an interconnected way (Brevi \& Gaetani, 2019). The Metadesign Studio provides a methodological path for the first design skills acquisition: techniques and research methods for understanding the product system, project context interpretation; and tools to elaborate and communicate the research till scenario building and concept generation. It provides both theoretical lessons and practical activities. The aim is defining and understanding the dynamics of the reference market - including users needs and behaviorsinvestigate the technological aspects and production methods related to the product under investigation and analyze the typological-formal values.

\section{Metadesign}

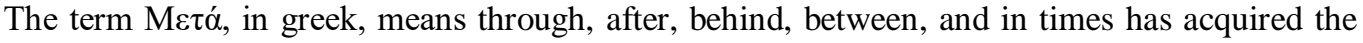
meaning of beyond, further than, so, in the specific context of our discipline, Metadesign means project of the project, organization of the project and has to deal with the initial discourse with a more general and more abstract dimension. In the educational context Metadesign studio is maybe a unique example and has the purpose of giving a method of work and to trigger meta-cognitive abilities. Metadesign studio at Polimi School is the place in which student experiments all the design phases starting from the fuzzy front end to the generation of the concept. Like in a role game they experience several steps analysing the world of constraints and the world of opportunities (Schön, 1983): (a) identify problem during context analysis (problem finding); (b) organize and shape informations on the different levels (problem setting), (c) grasp more evocative and inspirational inputs to nurture the project (trend analysis); (d) translate inspirations into project ingredients (scenario building); (e) synthesize stimuli in a bunch of concepts.

\subsection{Moodboards}

Moodboards are valuable tools for the design process because they are potentially produced in a short period of time - the activity lasts 1-2 weeks - and they can often provide directions and insights for the following time-consuming stages of design development.

Along our study path for educating the Industrial Designers mood can assumes different roles.

During the first year, developed in an experimental matter between the Methods Instruments for Design course and the Design Fundamentals Studio, moodboards are used to grasp and codify different 
aesthetical qualities with the aim of developing the student sensibility in translating and juxtaposing material and immaterial qualities as well as build a coherent product's aesthetic.

During the second year in the metadesign studio the aim of moodboards is double. On the one hand, moodboard are used as pre-project tool - allowing the students to communicate and narrate properly the values and the flavour of product prior to its existence and even before the concept phase - and represents the way to formalize one of the most immaterial part of the project. On the other hand, at the end of the process, the can be the most valuable tool to represent the more consistent and visible part of the project which is built by CMF Color Material and Finishing (Trini Castelli, 1999) that define the project feature in detail.

To guiding the students along the moodboard generation process, faculty ask them to select evocative images to deepen user's personality but also to connect these elements to other products or situations that characterize the user's lifestyle and the connected Aesthetical choices.

Figure 2. Product Design Process related to moodboard aims.

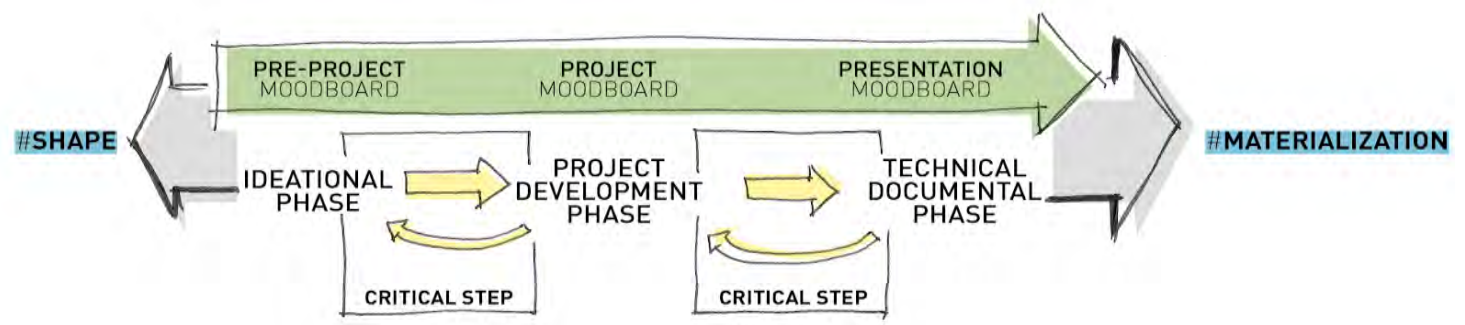

\subsection{Principles of creating moodboards}

Many studies on creative cognition suggest that creativity must be more than fun and wild imagination; realistic impact is also essential as the connection between reality, previous acquired knowledge and the capacity to creatively generate new knowledge. The use of visual notes, sketches, pictures, image gathering has a crucial role in the creative thinking performed by designers. Smith et al. (1995), analysing several authors approach to creative thinking, also assess that many studies converge on the fact that nonverbal processing, including visualization, often enhances creative insight. Visualization can be considered as a form of pre-invention as Finke (1990) epitomizes in his study on creative realism through a creative visualization research.

Figure 3. Moodboard positioning in the map of possible design research activities (actualized from Celi, 2011).

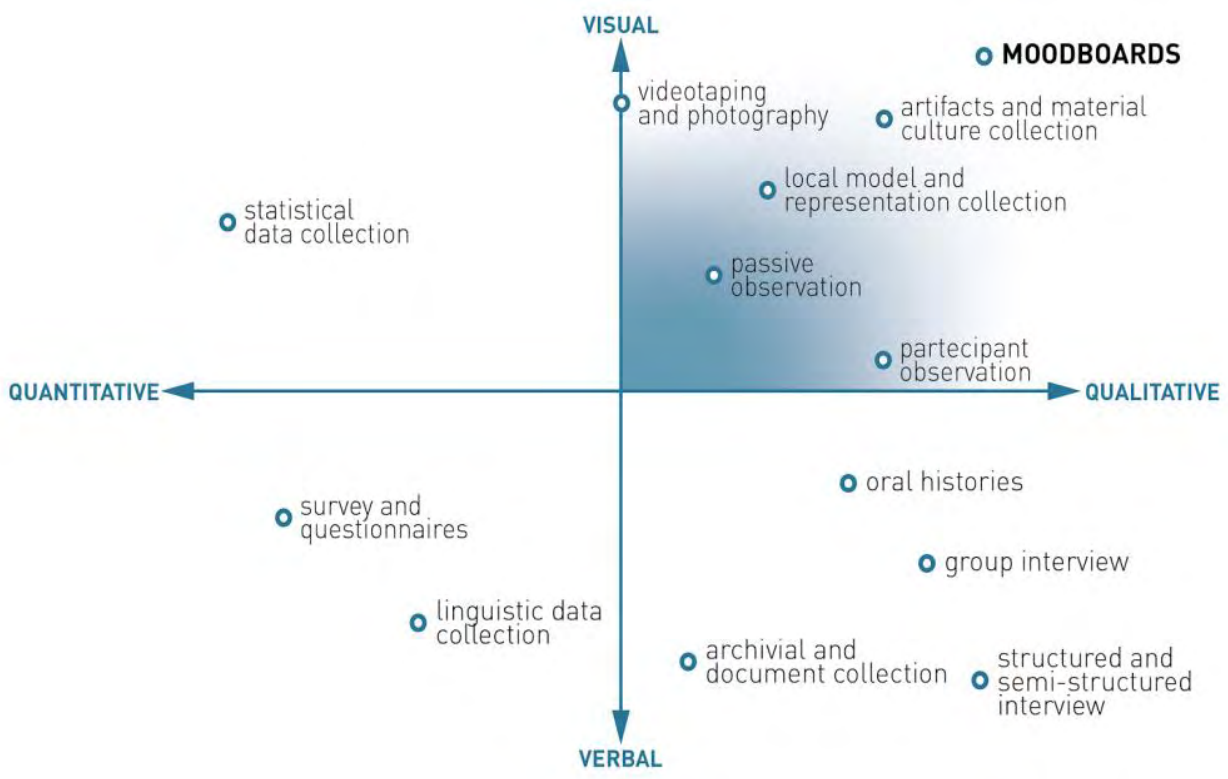

In this sense, Moodboards (Figure 3) represents the most qualitative and visual research that a designer may perform in the pre-project phase. They provide the design student with a rich background to nurture the creative process allowing the construction of a visual encyclopedia that offers inspirational 
themes, moods, colors, finishing, materials, details, product references, historical stylistic references, etc. - ready to be used into the design practice (Colombi \& Zindato, 2017). This practical tool is characterized by a strong visual dimension, the use of evocative images that are not "iconic" of the observed phenomena but that recall certain meanings using allegorical representations and narrative techniques. In this sense what seen from outside looks like a "collage" has a much more deeper meaning. Moodboard for example, are a way to build an aesthetic discourse preserving the historical path and image of a certain brand, or a valuable tool to transform something "old" through new qualities that respect the previous nature using assonance or contrast. they are a way to bridge past and future grasping seeds in present.

How design research can be expressed? When working on design topic, even if with a researcher approach, we need to use design tools. As Ochse suggests "creativity depends on technique, although, of course it goes beyond it. Routines provide creators with the symbols and the language of their culture: they provide sensory motor skill for artists, heuristics for scientist, vocabulary for poets "(Ochse, 1990).

The results of the explorations and the gathered materials in the form of pictures may are better exploitable if organized trough graphic mind map or in wall of evidences highlighting colours, shapes and different outlines, grid or composite styles may also be useful to assign weight and values to topics, aesthetics and specific languages.

How can we help undergraduate design student in realizing such kind of board and to develop the required sensibility? One of the methods that Metadesign courses use is the so called game of the "what if'. When students come to the difficulty of expressing trough images a certain value we ask them to imagine for example what kind of font could express that value? or if it was a famous painting, which painting would be? And if it was a pair of shoes? A car?... This kind of game helps student identify a certain lifestyle and connected products and languages. The next step is to convey them in a coherent representation.

\section{Tools for moodboards creation}

Methods and Instruments for Design course has been redesigned in the last two years to provide the basic skills on visual communication that will be request to students in other courses more focused on the design process, such as Metadesign Studio.

At the end of each lesson references for platforms and resources already available online are submitted to the class, after a selection on the basis of the quality required and to be aspired to, with the aim of deepening the topics covered in the classroom and of sustaining the students in the execution of the exercises (Gaetani, 2019). The exercises proposed aims to develop skills in creating moodboards; they are designed to develop the sensitivity of students to modify and create images, textures, patterns and color combinations (Sless, 1981). Initially, the students' ability to observe images is developed. Among the characteristics that students are asked to observe are: the interpretation of lights, shadows, colors, picture's cuts, figure/background ratio and focal length. In this phase they begin to create a collection of images that they pick up from topics expressed through adjectives, abstract concepts or other images of reference. The use of social media such as Pinterest allows the discovery of information through images.

Image editing software (e.g. Photoshop) is widely used for different purposes: (i) for the evaluation of image quality and its possible reproduction on physical media (printing) or digital media (screens); (ii) for editing; (iii) to create general or masked color variations as needed.

Vector image editing software (e.g. Illustrator) is used for creating simple boards and for creating custom textures and patterns.

\subsection{Case of study}

The final moodboard exercise summarises all the previous exercises and it is proposed starting from a reference image provided by the teacher. In addition to the board already assembled, individual images are also provided to allow editing. The basic colours are essentially two: black (the main one) and blue/light blue (the secondary one). At this point the students have to select a reference image for a new moodboard that has the same "mood" as the one provided, but with a different chromatic range. The choice is a critical phase: the request for similarity puts them in front of a selection criteria and at the same time they must be able to distance themselves, without banalising the supplied moodboard.

During this step the students must modify the images or find new ones that are more appropriate and coherent with the chosen reference image. The result is, in fact, a new moodboard, which retains the original character, but stands as an evolution of the previous one.

The process is similar to the one that would take place during a project development phase in which the moodboard is itself as a tool for the project evolution and it changes according to the phases and the project definition. 
Figure 4. Reference moodboard (on the left). Reference image (in the center) and modified moodboard (on the right).
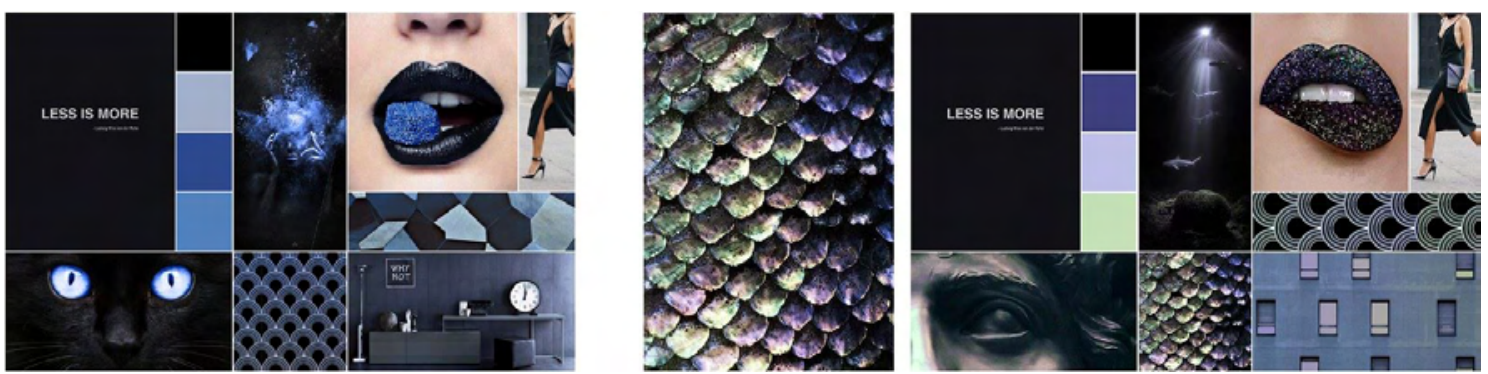

\section{Conclusions and acknowledgment}

The main purpose of this work is to enhance the sensitivity of students in the choice and selection of images during the early stages of their academic career. In this way they will be autonomous and proactive in Design Studios that they will face during their studies, during all the design process.

At Politecnico di Milano Design School we are trying to improve the effectiveness of representation courses by innovation in teaching activities. The case study highlighted in this paper is part of an ongoing basic research project, funded by the Politecnico di Milano Design Department ("Dal Segno alla Forma/From Sign to the Shape" funded by FARB - University Fund for Basic Research). The results are the outcomes of the first two years of experimentation (the second is still in progress).

Besides, the course contents and its management satisfied the students themselves. Indeed, on the basis of the students' opinions collected by the School of Design through a survey regularly done for every course just before the final exam, the satisfaction level has been effectively higher than the average of the School. In addition to the achievement of our expectations and to the score from the students' survey, we collected informal feedbacks by the other teachers involved in courses held in the same semester and in the next semester. They felt to have found a class better than usual for the quality of the works (drawings and graphics) that students were able to produce and for their ability to select research materials with a higher aesthetic level and more relevant to the task they were carrying out.

The paper is the result of common research and findings undertaken by the authors. Nevertheless, section 1 was edited by Fausto Brevi; section 2 was edited by Manuela Celi; section 3 was edited by Flora Gaetani.

\section{References}

Brevi, F., Celi, M., \& Gaetani, F. (2018). Developing representation skills for designers: evolution and trends in product design education, EDULEARN18 Proceedings (pp. 3677-3683). Palma, ES.

Brevi, F., \& Gaetani, F. (2019). Teaching and empowering representation skills for product design students, INTED2019 Proceedings (pp. 9533-9539). Valencia, ES.

Celi, M. (2011). Design, metadesign and the importance of vision, Proceedings of the 3rd International Forum of Design as a Process (pp. 247-259). Turin, IT: Allemandi.

Colombi, C., \& Zindato, D. (2017). Design Scenarios and Anticipation. In R. Poli (Eds.), Handbook of Anticipation (pp. 1-22). Springer International Publishing.

Finke, R. A. (1990). Creative imagery: Discoveries and inventions in visualization. Hillsdale, NJ: Eribaum.

Gaetani, F., Pinterest Boards. (2019). Retrieved 20 May, 2019, from https://www.pinterest.it/fgaetani/

Schön, D. A. (1983). The Reflective Practitioner: How Professionals Think in Action. New York, NY: Basic Books.

Sless, D. (1981). Learning and Visual Communication. London, UK: Croom Helm.

Smith, S. M., Ward, T. B., \& Finke, R. A. (1995). Cognitive processes in creative contexts. In S. M. Smith, T. B. Ward \& R. A. Finke, The creative cognition approach (pp. 1-7). Boston, MA: A Bradford Book.

Trini Castelli, C. (1999). Transitive design. A Design Language for the Zeroes, Milano, IT: Electa. 